\title{
Temas Emergentes em Ciências Sociais e Saúde Pública/Coletiva: a produção do conhecimento na sua interface'
}

\author{
Emerging Themes in Social Sciences and Public/Collective \\ Health: production of knowledge at its interface
}

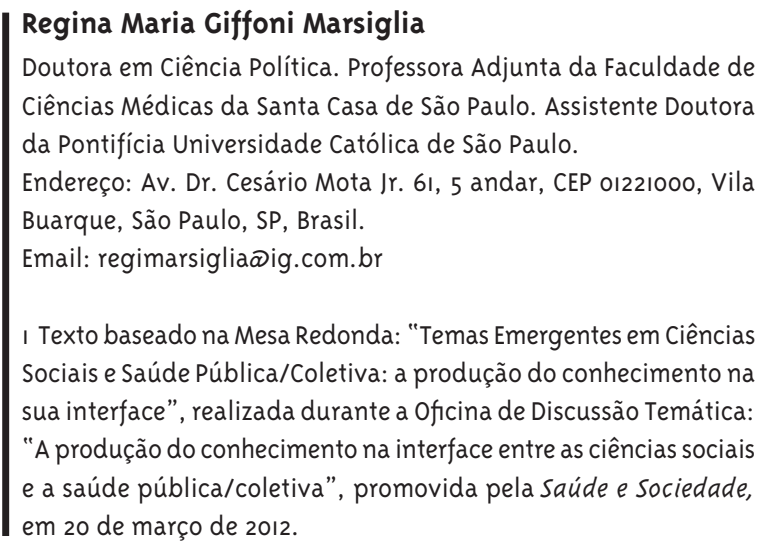

Doutora em Ciência Política. Professora Adjunta da Faculdade de Ciências Médicas da Santa Casa de São Paulo. Assistente Doutora da Pontifícia Universidade Católica de São Paulo.

Endereço: Av. Dr. Cesário Mota Jr. 6I, 5 andar, CEP 01221000, Vila Buarque, São Paulo, SP, Brasil.

Email: regimarsiglia®ig.com.br

I Texto baseado na Mesa Redonda: "Temas Emergentes em Ciências Sociais e Saúde Pública/Coletiva: a produção do conhecimento na sua interface", realizada durante a Oficina de Discussão Temática: "A produção do conhecimento na interface entre as ciências sociais e a saúde pública/coletiva", promovida pela saúde e sociedade, em 20 de março de 2012.

\section{Resumo}

Neste artigo, apontam- se inicialmente algumas questões fundamentais para o entendimento das relações entre ciências sociais e saúde desde o inicio do século XX. Posteriormente, discute-se a presença das ciências sociais na saúde pública e a constituição do campo da saúde coletiva, com a criação da Associação Brasileira de Pós- Graduação em Saúde Coletiva - ABRASCO, ao final dos anos 70. Aborda-se a definição de três eixos de pesquisa do novo campo - Política de Saúde e Organização de Serviços de Saúde, Condições de Vida e Saúde, Recursos Humanos na Saúde - e dois temas emergentes de pesquisa: trabalho e saúde, violência e saúde. Nos últimos tópicos, dedicado aos desafios para a produção do conhecimento na interface entre ciências sociais, saúde pública e saúde coletiva, a autora apresenta suas considerações sobre alguns pontos abordados por Amélia Cohn na Mesa Redonda promovida pela Revista Saúde e Sociedade em 20 de março de 2012 e os novos desafios, eixos de pesquisa e temas emergentes para a saúde coletiva e para as ciências sociais nesse campo, no contexto dos anos 2000.

Palavras-chave: Ciências Sociais; Saúde Pública; Saúde Coletiva; Eixos de Pesquisa; Temas Emergentes; Desafios. 


\section{Abstract}

In this article, we firstly point out some fundamental questions to understand the relationship between Social Sciences and Health from the beginning of the 2oth century.The presence of Social Sciences in Public Health is discussed, as well as the constitution of the field of Collective Health, with the creation of the Associação Brasileira de Pós Graduação em Saúde Coletiva- ABRASCO ("Brazilian Association of Post Graduation in Collective Health"), in the late 70's; the definition of three research lines in the new area: Health Policies and Health Service Organization, Life and Health Conditions, Human Resources in Health; and two emerging research themes: Work and Health, and Violence and Health. In the last topics, dedicated to the challenges in knowledge production at the interface of Social Sciences, Public Health and Collective Health, the author presents her considerations on some points discussed by Amélia Cohn by occasion of a Round Table organized by Revista Saúde e Sociedade ("Health and Society Magazine") on March 20 ${ }^{\text {th }}, 2012$, and the new challenges, research lines and emerging themes for collective health and for social sciences in this area, in the context of the years 2000.

Keywords: Social Sciences; Public Health; Collective Health; Research Lines; Emerging Themes; Challenges.

\section{Introdução}

O primeiro ponto a discutir é o entendimento do que seja "Saúde Publica" enquanto campo de conhecimentos e práticas, historicamente constituído a partir do desenvolvimento das grandes Monarquias Nacionais, ao final da Idade Média na Europa. Esse campo se desenvolveu diante da necessidade de enfrentamento das grandes epidemias que ameaçavam a fase de acumulação primitiva do capital e a viabilização dos investimentos para subsidiar as grandes navegações, que partiam em busca de riquezas, produtos para comercializar e novas terras a explorar.

Outro ponto a considerar são as diferentes noções do que venha a ser "público", termo caracterizado pela polissemia: ora é entendido como sinônimo de "população", como referência a "coletividades" em oposição a indivíduos isolados; ora como referência a "interesses coletivos" ou "ao bem comum", ao invés de interesses individuais ou de grupos particulares.

\section{Ciências Sociais e Saúde: relações}

\section{antigas}

Nunes (1999) ressalta o trabalho pioneiro do médico Sigerist (1929) que, ao tratar o doente no contexto da sociedade, contribuiu profundamente para a construção do campo da sociologia médica nos Estados Unidos e para a explicação da biologia em uma matriz ao mesmo tempo histórica, social, política e econômica e As questões relacionadas à morte e à doença também foram abordadas nos estudos sobre vários povos, em diferentes contextos históricos e sociais. Minayo (2006) aponta como desde o início do século XX, as reflexões dos antropólogos têm contribuído de forma importante para o setor saúde: Marcel Mauss (1950), nas discussões sobre as relações entre o fisiológico, o emocional, as práticas culturais e o contexto social; Lévi-Strauss (1963), sobre a morte no contexto das visões de mundo e das representações coletivas, o papel das terapêuticas e da cura nos sistemas simbólicos e nas relações sociais e a eficácia simbólica da relação de confiança interativa entre médico, paciente e as expectativas do grupo social a que pertence.

Na América Latina e no Brasil, a incorporação 
de conhecimentos da área de Ciências Sociais e Humanas pela Saúde Pública ficou mais evidente por volta dos anos 50, já sob influência americana e das agencias internacionais, como a OMS e OPAS: no paradigma da medicina preventiva, desenvolvido por Leavell e Clark (1976), é possível perceber o recurso a conhecimentos produzidos pela etnografia e antropologia, que passaram a contribuir para as práticas de educação sanitária e medicina preventiva.

Ratificando esta afirmação, Canesqui (1997) considera que a presença das ciências sociais na pesquisa social em saúde, bem como na formação dos profissionais do campo biomédico e sanitário, não é nova no Brasil, acompanhando os diferentes movimentos de reforma do ensino e da atenção: medicina integral, medicina preventiva e medicina comunitária.

Para Nunes (1999), no entanto, apesar desses antecedentes, apenas a partir dos anos 6o é que as ciências sociais passaram a ser incorporadas de forma mais sistemática, nos cursos de graduação em medicina, associadas à epidemiologia, ciências da conduta, administração de serviços de saúde, bioestatística, visando fornecer uma visão mais completa do indivíduo. Isso se deu devido às críticas sobre o modelo biomédico dominante na formação dos médicos.

Ao mesmo tempo, ao final dos anos 6o, é possível perceber em alguns estudos a emergência de críticas às Ciências da Conduta por não abordarem os processos sociais e as condições de saúde, apontando para a necessidade de se incorporar explicações mais abrangentes e macroestruturais, produzidas no âmbito da sociologia e da ciência política (Canesqui, 1995).

Muitas destas discussões estavam em consonância com o debate que se processava no interior das ciências humanas e sociais no Brasil e América Latina. Tentava-se produzir conhecimentos que dessem conta da particularidade da formação histórico-social destes países que haviam participado do sistema colonial nas fases de acumulação primitiva e concorrencial do capitalismo: enquanto ex- colônias, consideravam insuficientes as explicações da teoria da dependência (Bobbio e col., 1986). Muito embora, como afirma Nunes (1999), alguns analistas considerem que foi no período das discussões sobre a situação de dependência dos seus países que o pensamento latino- americano apresentou um marco interpretativo original, partindo das relações entre centro e periferia, no desenvolvimento do capitalismo. Intelectuais e militantes, recorrendo ao materialismo histórico estrutural, criticavam as teses sobre o futuro do Brasil e da América latina, buscando entender a singularidade dessas formações sociais, os caminhos do desenvolvimento, as possibilidades de mudanças sociais ou de transformação social (Figueredo, 2004).

\section{Movimento da Reforma Sanitária e Constituição do Campo da Saúde Coletiva no Brasil}

A partir dos anos 70, durante a vigência da Ditadura Militar instaurada a partir de 1964, vários fatores de ordem política, social e intelectual propiciaram o desenvolvimento do movimento social que ficaria depois conhecido como Movimento da Reforma Sanitária no país. O“Partido Sanitário”, como se referiam seus militantes à organização do movimento, porque articulou tendências e forças políticas de várias origens, pode ser considerado como intelectual orgânico, vocalizador de interesses de classes e segmentos sociais diferentes naquele contexto, no sentido utilizado por Gramsci (1978).

Desde o início dos anos 70, professores, profissionais e estudantes reunidos em torno dos Departamentos de Medicina Preventiva ou de outras denominações, como Medicina Social, Saúde Pública, Saúde Comunitária, passaram a realizar encontros e discussões para definir as disciplinas e conteúdos que deveriam ministrar em suas disciplinas, especialmente nos cursos de graduação de medicina, de especialização em Saúde Pública e do primeiro curso de pós-graduação em Medicina Social, na UERJ, em 1974.

Desenvolveu-se nesse processo uma posição de crítica sobre a realidade médica e social e a prática da medicinaque resultou na produção de trabalhos acadêmicos como os de Donnangelo (1975), Donnangelo e Pereira (1979), Luz (1978) e Arouca (2003), dentre outros. Esse processo e essa produção acabaram por constituir as bases conceituais que subsidiaram 
a definição do campo da Saúde Coletiva e a fundação da Associação Brasileira de Pós- em Saúde Coletiva - ABRASCO, em 1979, na I Reunião sobre Formação e Utilização de Pessoal de Nível Superior na Área de Saúde Coletiva, realizada em Brasília pelos Ministérios da Educação, Saúde, Previdência e Assistência Social com apoio da Organização Pan-Americana da Saúde (Belisário, 2002).

Vários autores procuraram definir que novo campo era esse, como aponta Nunes (2006a). Dentre eles, Donnangelo (1983) faz referência a uma multiplicidade de objetos e áreas de saber; Fleury Teixeira (1992) o considera como uma criação brasileira para enfrentar as diferentes denominações de medicina preventiva, medicina social, saúde pública e saúde comunitária; Pombo, (2003) o descreve como um campo multiparadigmático, com diferentes tipos de disciplinas, desde as ciências naturais até às sociais e humanas. A definição do próprio Nunes (2006b) usa a imagem de um mosaico, formado por partes separadas que se aproximam para a compreensão dos problemas e elaboração de propostas que se situam além dos limites de cada "campo disciplinar", exigindo arranjos interdisciplinares.

Canesqui (1997) considera a saúde coletiva como um campo em constituição, marcado por tensões epistemológicas e por inflexões de natureza políticoideológica. Isto decorre da reunião de correntes de pensamento e de práticas associadas ao campo médico sanitário, vertentes modernizantes da medicina previdenciária e programas de extensão da cobertura da atenção à saúde.

O campo da saúde coletiva acabou por apresentar, já na sua origem, três áreas e formações disciplinares: a das ciências sociais (mais recentemente, das ciências humanas e sociais), da epidemiologia, e da administração e planejamento (mais recentemente, denominada de política e planejamento).

Outra questão que apareceu desde o início no campo da saúde coletiva como de fundamental importância foi a polissemia do termo "coletivo", ora usado como sinônimo de "população" por oposição ao indivíduo, ora como sinônimo de "social" por oposição ao "individual", ora como sinônimo de "público" por oposição ao "privado", ora como "epidemiológico" por oposição à "clinica”.

Mas hoje, depois de mais de três décadas de constituição do campo, com o desenvolvimento conceitual e a implantação das políticas de saúde e das práticas no setor saúde, essas oposições são muito menos nítidas. Em muitos trabalhos e abordagens busca-se, ao contrário, estabelecer as relações e "as pontes" entre "o indivíduo e a sociedade", o "sujeito e o coletivo", a "clínica e a epidemiologia”, a objetividade e a subjetividade, até mesmo entre o "público e o privado".

\section{Linhas de Investigação na Saúde Coletiva}

A Saúde Coletiva, quando se constituiu como campo, apontou sua especificidade no campo da investigação científica, centrando as pesquisas, as propostas de ação e a formação de profissionais em três grandes eixos:

1 - A previdência social, a política de saúde, o sistema de saúde e organização dos serviços de saúde. Buscava-se o acesso de todas as camadas da população aos serviços de saúde, movimento que culminou na proposta do Sistema Único de Saúde - SUS na Constituição Federal de 1988, um sistema universal, equânime, integral, descentralizado, hierarquizado e sob controle da sociedade cível organizada. Para tal controle, defendia-se a realização de conferencias de saúde periódicas e a implantação de conselhos de saúde em todos os níveis do sistema;

2 - As relações entre as condições de saúde e as condições de vida a que estavam submetidos as diversas classes, estratos e camadas sociais, que se refletiam no perfil de morbimortalidade da população;

3 - A questão dos recursos humanos para a saúde, considerando-se sua dimensão, perfil, distribuição, mercado de trabalho, características dos processos de trabalho, formação;

Além desses eixos, dois outros temas foram apontados como emergentes naquele contexto histórico e social. 0 primeiro é o das relações entre trabalho e saúde. Considerava-se que tais relações não eram adequadamente abordadas do ponto de vista social até aquele momento, embora já existissem a Medicina do Trabalho como especialidade médica e a Consolidação das Leis do Trabalho- CLT no país, desde os anos 40. Defendia-se uma nova abordagem 
conceitual e política sobre as relações entre Saúde e Trabalho, que foi sendo elaborada e incorporada na análise a partir dos trabalhos de Dejours (1987) e Laurell e Noriega (1989), dentre outros autores.

O outro tema também considerado pelo campo como emergente foi o da violência, dos acidentes e do aumento da morbimortalidade da população no país por causas externas, especialmente nas capitais e grandes centros urbanos.

As discussões sobre diversidade, desigualdades de gênero, etnias, exclusão e discriminação de determinados grupos sociais apareceu posteriormente nas discussões do campo, já em meados dos anos 8 o.

\section{Incorporação das Ciências Humanas e Sociais na Saúde Coletiva}

No início dos anos 40 a incorporação da antropologia e dos estudos etnográficos foi bem aceita na Saúde Pública, mas, na constituição do campo da Saúde Coletiva entre os anos 70 e início dos anos 8o, o arcabouço conceitual da sociologia foi mais facilmente assimilado: nas análises macro-estruturais e históricas da sociedade brasileira e das relações de produção e consumo com o perfil de morbimortalidade da população; na análise das profissões da saúde através da incorporação do materialismo histórico e estrutural. Loyola e Machado (1979) traduziram e organizaram o livro de Boltanski (1979), "As classes sociais e o corpo", uma abordagem que articulava conhecimentos de sociologia e antropologia; Loyola publicou seu próprio livro, nessa mesma perspectiva: "Médicos e Curandeiros: conflito social e saúde" em 1984.

Já no início dos anos 8o, quando do desenvolvimento do Movimento da Reforma Sanitária em direção à proposta de um Sistema Único de Saúde - SUS, que culminou com sua incorporação na Constituição Federal de 1988, a teoria política foi mais procurada para embasar essa luta. Posteriormente, face aos desafios para a implantação do SUS, conhecimentos da administração e planejamento foram incentivados e conseguiram espaço no campo da saúde coletiva. E a antropologia voltou a fornecer subsídios, para a compreensão das representações sobre o processo saúde-doença pelos diferentes segmentos da população.
Marsiglia e Spinelli (1983), ao comentar o levantamento realizado sobre os conteúdos ministrados nos cursos de pós- graduação em Saúde Coletiva no país, consideravam que nos anos 8 o houve predominância dos conceitos originados da sociologia e da economia política, como modo de produção e classes sociais, ou conceitos originários da ciência política, como estado, ideologia, políticas sociais, hegemonia e instituições sociais. .

Dez anos depois, Marsiglia e L'Abbate (1994) avaliaram que, embora conceitos da ciência política e economia política ainda fossem bastante utilizados nos cursos de ciências sociais na saúde coletiva, tanto de graduação quanto de pós-graduação latu ou stricto sensu, também haviam sido incorporados nos programas conceitos de sociologia e de antropologia, especialmente através das discussões sobre classes sociais, representações sociais e práticas e sistemas populares de cura.

Canesqui (1997) aponta que as ciências sociais receberam diferentes denominações no campo da saúde coletiva, mas há consenso de que foram incorporadas distintas perspectivas de análise e de que existiam sérias dificuldades para a efetivação da interdisciplinaridade entre as próprias ciências sociais "ao se debruçarem" sobre a saúde como objeto de suas pesquisas.

Gomes (1994) mostrava preocupação, em seminário sobre as ciências sociais na saúde ocorrido no início dos anos 9o, em recuperar a antropologia no campo da Saúde Coletiva, que no seu entender fora estigmatizada nos anos 1970 e início dos anos 1980 como área retrógrada, que não colaborava para as mudanças na sociedade e na área da saúde pois procurava adequar os indivíduos ao sistema social.

Minayo (2006), ao contrário, considera que a antropologia clássica sempre contribuiu para a discussão do processo saúde-doença, de várias perspectivas: relativizando os conceitos biomédicos, desvendando a estrutura dos mecanismos terapêuticos, apontando as relações entre saúde-doença e realidade social, na contextualização dos sujeitos e as formas de abordagem do processo saúde-doença. Ela conclui que a vivência da saúde e da doença produz efeitos e traz consequências tanto para o corpo quanto para o imaginário; por isso, os profissionais de saúde devem considerar os valores, atitudes e 
crenças das pessoas, ampliando suas bases conceituais e permitindo uma abordagem mais abrangente dos fenômenos com que lidam.

Ao referir-se ao estudo das políticas de saúde na saúde coletiva, Cohn (2006) considera que o tema sempre ocupou um lugar central no campo, constituindo-se simultaneamente num campo de conhecimento e de práticas, orientando a formulação da própria política. Essa característica, como bem assinala a autora, tem propiciado grande tensão na área, em virtude da disputa entre a dimensão técnica e a dimensão política nos processo de tomada de decisão, (Cohn, 2006).

Mais recentemente, no V Congresso de Ciências Sociais e Humanas realizado pela Comissão de Ciências Sociais e Humanas da ABRASCO, em São Paulo, em abril de 2011, novas produções foram apresentadas, dentre as quais destacamos as de Barsaglini (2011) com um enfoque antropológico sobre o Diabetes e a de Gomez e colaboradores (2011), sobre a configuração e transformações da área da saúde do trabalhador.

\section{Desafios no processo de Incorporação das Ciências Sociais e Humanas na Saúde Coletiva}

Os desafios que as ciências humanas e sociais enfrentam no campo da Saúde Coletiva não começaram com o desenvolvimento desse campo. Muito embora as ciências sociais e humanas sempre tenham se debruçado sobre as questões da doença e da saúde, fizeram-no historicamente, pensando essas questões como "parte" da vida em sociedade, e não dirigindo seu olhar para o ângulo específico da saúde ou da doença.

Os cientistas sociais presentes no I Encontro Brasileiro de Ciências Sociais em Saúde realizado em 1993 em Minas Gerais, já apontavam as dificuldades encontradas para 'traduzir' a linguagem e os métodos das Ciências Sociais para áreas em que o objeto foi tradicionalmente considerado como 'privativo' das ciências naturais, fato que ocorre na área de saúde" (Marsiglia e L’Abbate, 1994, p. 134).

As ciências sociais, como as outras ciências, também partem do conhecimento empírico sobre a realidade para desenvolver seu conhecimento. Elas acabam por construir um objeto abstrato que exige distanciamento do real e elaboraram teorias com certo grau de generalidade, como é o propósito de qualquer ciência. No entanto, na sua incorporação pela saúde, as ciências sociais foram chamadas para discutir situações concretas e particulares e contribuir para a resolução dos "problemas" encontrados; a resposta a questões concretas não é ou pelo menos não era um "hábito" dessas ciências, pensadas como áreas e disciplinas do conhecimento. Diferentemente, a educação, o serviço social e a administração são áreas com maior tradição profissional, que formam pessoas mais habilitadas para as exigências decorrentes de processos de intervenção imediata na realidade social.

Como havia da parte das ciências sociais a necessidade de guardar certo distanciamento da realidade, o chamado para a intervenção ou para indicar um modo de intervir a partir do conhecimento que produziam, soava "estranho" e causava muito "desconforto" nos cientistas, que encontravam inúmeras dificuldades em "fazer a passagem do conhecimento teórico" para prescrições concretas de ação.

Outro desafio importante para cientistas sociais que se inserem na área da saúde pública ou saúde coletiva são as relações que devem ser estabelecidas entre a abordagem epidemiológica e a abordagem social; Cohn, neste evento, chamou-as de "caixa preta”, referindo-se a uma relação que não está bem explicada e que, como todo tipo de relação, envolve questões relativas à detenção e exercício de poder.

A natureza da saúde e da doença, enquanto objeto do conhecimento, constitui outra questão desafiadora para as ciências sociais na saúde coletiva: Latour (1994), . ao abordar a doença enquanto processo determinado pelas relações recíprocas entre a configuração biológica e sua inserção na realidade construída socialmente, cunhou a expressão "hibrido biológico- social". Do meu ponto de vista, prefiro não usar essa expressão, porque parto da ideia de que não há biológico humano fora da sociedade, (a não ser uma ou outra exceção, como dos meninos-lobo, que nem mesmo desenvolveram todas as potencialidades humanas). Considero a doença ou a saúde como uma unidade não linear ou homogênea, por vezes conflitiva ou contraditória, resultado da unidade natureza-sociedade. 
Mas sabemos que no processo histórico de desenvolvimento do conhecimento científico, essa unidade foi quebrada, quando os pesquisadores das ciências naturais e biológicas "tiraram"o homem da sociedade e os cientistas humanos e sociais "deixaram de lado" o caráter biológico dos homens que estudavam: os estudos sobre as sociedades humanas, não contemplaram o caráter anatômico e fisiológico dos seres, ou se quisermos, da espécie que estava envolvida e dava substrato ao desenvolvimento das formações sociais; poucos se preocuparam em apontar como essas formações sociais se refletiam sobre o biológico humano. Por outro lado, os estudos empreendidos pela biologia humana não consideraram o ser humano dentro do contexto social e histórico em que estava inserido. Cada uma dessas áreas da ciência ignorou a complexidade e unidade que constitui o objeto de seu conhecimento: o ser humano, ser biológico sempre em relação com a natureza através das relações com outros seres da mesma espécie. Considero que esta é uma questão que deve ser pensada e atualizada pela constante discussão sobre as relações entre natureza e sociedade e sobre a especificidade dessa relação, quando se trata do ser humano, histórico e social por natureza.

Birman (1991) aborda em parte essa questão, ao reforçar a perspectiva do caráter multidisciplinar do campo da saúde coletiva. Ele decorre da diversidade de seus objetos e discursos em torno da saúde e do fato de que a problemática básica desse campo são as relações entre a natureza e cultura, sugerindo que a saúde diz respeito a um corpo simbólico, regulado culturalmente e condicionado pela sociedade, que em geral é marcada por diferenças sociais. Portanto, não pode ser pensado apenas como um corpo ou organismo biológico puro.

Por outro lado, é importante lembrar que o desenvolvimento histórico das ciências humanas e sociais também ocorreu através da constituição de várias disciplinas: antropologia, sociologia, política, história, com certa autonomia entre elas. Canesqui (1997), ao discutir a questão das ciências sociais no campo da saúde coletiva, lembra que

ainda existem sérias dificuldades para que se efetive a interdisciplinaridade entre as próprias ciências sociais, quando se debruçam sobre o tema saúde e entre essas e um conjunto heterogêneo de disciplinas que compõem a saúde coletiva... a consolidação (da interdisciplinaridade) enfrenta obstáculos, dada a demarcação das fronteiras entre as disciplinas, envolvendo questões de natureza epistemológica, institucionais, de relações de força e poder entre elas... (Canesqui, 1997, p. 13).

No entanto, é importante mencionar que vivemos na Pós Modernidade, diante do questionamento do pensamento puramente cartesiano como insuficiente para fazer avançar o conhecimento sobre objetos e processos complexos. É preciso reconhecer que essa perspectiva de ciência, baseada na estratégia de abordar objetos complexos fragmentando-os em elementos simples para o estudo e depois procurando explicar sua contribuição para a compreensão do todo, foi propulsora do avanço do conhecimento por mais de três séculos, especialmente nas ciências físicas e naturais, mas também com influência nas ciências humanas e sociais.

Hoje, as questões que o conhecimento científico tem que enfrentar exigem abordagens mais articuladas que busquem tomar, desde o início a perspectiva de conhecer a totalidade que se reproduz em todos os elementos e fragmentos da realidade, mesmo nos considerados mais simples e elementares: é fundamental que se parta da perspectiva de que o "real”, "o concreto, é constituído pela síntese de múltiplas determinações", unidade da diversidade, como afirmou Marx (1977) e que cada parte contem o "todo". Outros autores, como Morin (2001), propõem que se "religue" o conhecimento produzido pelas ciências físicas e naturais, pelas humanas e sociais, bem como as várias expressões da arte. Vivemos atualmente esse desafio no campo da saúde coletiva.

Outra questão apontada no debate é o fato das ciências sociais "cederem" partes de seu objeto ao serem incorporadas no campo da saúde coletiva, porque nesse campo já havia outro conhecimento “instalado", com objeto, metodologia, conceitos e teorias consolidadas, e detendo maior poder no interior desse campo. As ciências recém-chegadas acabaram por ocupar uma "posição subordinada", e foram de certa forma "constrangidas" a oferecer respostas imediatas às demandas de outras disciplinas já instaladas no campo, sem que pudessem apresentar suas próprias perguntas e demandas decorrentes do 
objeto com que trabalham, das teorias e conceitos em que se baseiam e dos métodos em que estão assentadas suas investigações.

Será possível produzir um conhecimento que não seja subordinado na interface das ciências naturais com as ciências humanas e sociais? Penso que sim, se conseguirmos olhar conjuntamente para o objeto real, concreto, complexo, conflituoso e contraditório que se nos apresenta no campo da saúde coletiva; sem nos deixarmos tentar pela idéia de fragmentá-lo, e sim preocupados em abordá-lo como uma unidade, respeitando essa unidade. É claro que, pela nossa experiência secular anterior, cada ciência, cada cientista, cada pesquisador ou cada profissional apresentam imensa dificuldade para se despir de seu próprio olhar, já consolidado, voltado para determinados "ângulos" do real; seu olhar e seu impulso para conhecer e pesquisar já vêm direcionados, previa e seletivamente, para determinada direção.

Há uma questão que quero apontar ainda, que considero de suma importância no contexto atual, especialmente no interior das ciências sociais: como usar a teoria social produzida, parte dela em um nível importante de abstração e generalidade, para subsidiar a análise de processos reais concretos, de realidades históricas e sociais singulares? É preciso fazer "as mediações", como frequentemente afirmamos, usar conceitos e métodos que melhor consigam explicar a historicidade, a singularidade e particularidade dos processos que se nos apresentam para conhecer, sem deixar de lado as determinações gerais que em última instância condicionaram essas realidades concretas e particulares.

Ressalto aqui a importância de revalorizarmos o conceito de formação social que permeou as preocupações de nossos cientistas sociais, especialmente nos anos 6o e 70, no afã de explicar a realidade latino americana e brasileira. Hainecker, Balibar, Stavenhagem, Cuevas, Gunder Frank, Faletto, F. H. Cardoso, Luis Pereira e Otavio Ianni, dentre outros, qualificaram as discussões sobre o desenvolvimento nos países que foram colonizados a partir do século XIV., É importante lembrar a ebulição dos debates no campo das ciências sociais na América Latina nessas décadas, que tentavam pensar as perspectivas do desenvolvimento e da mudança social em nossos países, inseridos na periferia do sistema capitalista internacional, bem como nos estudos dos que se preocuparam em explicar o capitalismo europeu, especialmente na Itália, como Gramsci (Bobbio e col., 1986).

Estudos sobre formações sociais concretas e históricas no interior do capitalismo poderão nos afastar no contexto atual de duas tendências igualmente inadequadas para o avanço do conhecimento: do teoricismo, que sempre se refere aos objetos construídos abstratamente, e do empiricismo, das abordagens particularistas, de saturações empíricas, que não conseguem apontar e separar as tendências determinantes daquilo que é singular, particular, ou mesmo circunstancial na realidade.

De muitas formas, o Movimento da Reforma Sanitária no Brasil, que foi fundamental para a definição da área da saúde coletiva ao final dos anos 70, acompanhou esse processo. Considero que esse movimento foi bem sucedido porque conseguiu definir uma política de saúde universal e desenhar a proposta de um sistema único de Saúde para o país - o SUS - e inscrevê-los na Constituição Federal de 1988; ao mesmo tempo, foi responsável pela "criação" de um novo campo de conhecimentos, a saúde coletiva, nascido da articulação desafiadora e conflituosa entre conhecimentos originários de várias áreas, de disciplinas que utilizam metodologias diferentes para apreender a realidade; e que ultimamente, juntamente com outros movimentos e instituições da área da saúde, vem influindo na discussão sobre a formação de futuros profissionais e docentes para a área.

Concordo com a Amélia Cohn de que a discussão sobre os determinantes sociais na saúde tem apresentado muitas dificuldades, especialmente quando alguns trabalhos tentam ou tentaram operacionalizar o conceito de classe social, um conceito analítico da teoria marxista. Considero que trabalhar com o conceito de desigualdade social e seus reflexos sobre a saúde, perfil de morbimortalidade, expectativa de vida e acesso ao sistema de saúde dos diferentes estratos sociais da população é mais facilmente passível de ser mensurado e pode trazer indicações importantes para o planejamento das ações na área da saúde voltadas para a correção ou pelo menos compensação dessas diferenças. É importante lem- 
brar que na Classificação Internacional das Doenças - CID - já há um capítulo destinado a caracterizar as circunstâncias socioeconômicas e psicossociais que influem no estado de saúde e relação com os serviços de saúde (OMS, 2008) Eixos de pesquisa no campo da saúde coletiva no contexto dos anos 2000.

Quais são os temas emergentes atualmente na saúde, que desafiam o campo da saúde coletiva e a contribuição das ciências sociais e humanas? Permanecem os mesmos três grandes eixos apontados no início dos anos 8o, e os mesmos temas emergentes? Os eixos permanecem, mas com novos desafios. Além disso, também emergiram outros temas que não se colocavam há zo anos.

\section{Eixo: Políticas de Saúde e Organização dos Serviços de Saúde}

O princípio da universalização do atendimento ainda não foi completamente efetivado, mas é preciso reconhecer que houve uma extensão importante da cobertura do sistema para muitos segmentos da população que não tinham nenhum acesso aos serviços de saúde. A equidade no acesso aos serviços e aos diferentes níveis de atenção, no entanto, ainda deixa muito a desejar: os desafios atuais dizem respeito a como conhecer as necessidades e desenvolver práticas na área da saúde dirigidas a segmentos da população que vivem muito distantes de qualquer serviço de saúde ou que vivem em situação de pobreza extrema em áreas urbanas; como atuar para diminuir as desigualdades no acesso, eficiência, eficácia e efetividade das ações desenvolvidas nos serviços de saúde, quando conseguem incorporar esses segmentos sociais.

Neste aspecto, há uma discussão importante que vem sendo desenvolvida na área das políticas sociais: a proposição de ações específicas ou mesmo de programas dirigidos a esses segmentos implicaria em focalizar a atenção no SUS, rompendo com o princípio de universalidade? Propostas de "discriminação positiva" podem constituir-se apenas em "disfarces" para a focalização da política e dos programas assistenciais, ou colaboram para a promoção da equidade e universalização do sistema? São estratégias necessárias para se garantir o acesso de todos os segmentos da população aos serviços, em sociedades que se caracterizam por grandes desigualdades sociais e regionais?

Um aspecto importante nesta discussão foi colocado pela Amélia Cohn no debate: quando estamos falando de políticas, programas ou estratégias especiais para atender necessidades particulares ou grupos particulares, além de ressaltarmos o que cada segmento apresenta como necessidades específicas, devemos apontar também o que ele tem "em comum" com o restante da população.

E a produção cientifica deve contribuir para o enfrentamento destas questões: promoção da equidade, contemplar as diferenças de gênero, etnia, geração, ciclo de vida, inserção em áreas urbanas, metropolitanas, rural, litorâneas, ribeirinhas, sem que isto leve a desigualdades na atenção, mas ao mesmo tempo, evitando considerar que a garantia de direitos seja sinônimo de homogeneização e burocratização na atenção.

\section{Eixo: Condições de Vida e Trabalho}

As condições de vida atuais determinam problemas referentes às mudanças no processo produtivo, ao acesso a alimentos e novos padrões nutricionais, a mudanças no perfil etário e de morbimortalidade da população: a obesidade, as neoplasias, as doenças profissionais e a predominância das doenças crônico-degenerativas dependem da adesão dos usuários e mudanças de comportamento, de estilos de vida, para que possam ser enfrentados. Esses aspectos exigem mudanças nas práticas, funcionamento e organização dos serviços, a preocupação com o atendimento contínuo, a articulação entre os vários níveis de atenção, a criação de vínculos e democratização do conhecimento.

\section{Eixo: Recursos Humanos em Saúde}

Nestas últimas décadas também ocorreram profundas mudanças nos processos de trabalho na área de saúde, no mercado de trabalho, nas relações de trabalho, como a terceirização dos trabalhadores, a privatização e precarização nas formas de contratação. Ao mesmo tempo, há novas exigências para a formação das várias profissões da área de saúde. Há necessidade de se repensar as bases conceituais 
da sociologia das profissões, de novas pesquisas. As concepções sobre profissões e ocupações, consolidadas nos séculos XIX e XX, precisam ser revisitadas: competências, monopólio do conhecimento, éticas profissionais, devem ser rediscutidas face às novas exigências de trabalho e dos princípios do SUS.

Há ainda um problema a ser enfrentado: é essa postura "anti” serviço público, a avaliação negativa do serviço público, que aparece entre os profissionais, mas também entre a população e é constantemente alimentada pela mídia e pelos meios de comunicação, de forma bem generalizada. É claro que nossa história de patrimonialismo no trato da coisa pública, deixou marcas profundas na prática política, na prestação de serviços públicos e no imaginário coletivo, mas precisa ser enfrentada na formação dos recursos humanos e na organização e funcionamento dos serviços de saúde.

Outro ponto é importante no processo de construção de um sistema de saúde que se pretende universal, equânime, integral e público: embora haja um discurso sobre descentralização e participação, a administração pública ainda é muito centralizada, normativa e prescritiva. Esta tendência acaba sendo reforçada pela falta de visão de que as políticas públicas, como a de saúde, são políticas de estado, não de administrações transitórias e partidos políticos no poder. Há que considerar o fato de que nos níveis intermediários das administrações públicas os profissionais no exercício de suas atividades não conseguem, por várias razões que não vamos discutir agora, assumir a posição de protagonistas, na defesa do princípio constitucional da saúde como direito de todos e dever do Estado.

\section{Temas Emergentes na Saúde Coletiva no Contexto dos anos 2000}

A questão da violência, que era tida como emergente, tornou-se uma questão central para o campo da saúde coletiva: disseminada, diferenciada, aparece em todas as regiões, e especialmente nas áreas metropolitanas, como terceira ou segunda causa de mortalidade ou de incapacidade precoce, de procura por serviços de urgência, emergência e reabilitação no país.

Quanto ao tema das relações entre trabalho e saúde, novas questões se apresentaram nestes últimos trinta anos, e outras já existentes se intensificaram. Chama a atenção no país a intensificação dos processos migratórios de latino americanos e asiáticos, especialmente para os grandes centros urbanos do país, e de refugiados de outros países, especialmente africanos. Acabam por inserir-se como força de trabalho em alguns ramos de produção, caracterizados pela precarização nas relações de trabalho, riscos de acidentes e doenças profissionais, não direitos trabalhistas e previdenciários.

Esses processos migratórios têm levado a processos de desterritorialização desses grupos populacionais, bem como ao desenvolvimento de formas de sociabilidade segmentadas e competitivas, não só no mercado de trabalho, mas nos espaços sociais, que geram situações de violência e conflito social.

A estes, somam-se os problemas decorrentes do crescimento de segmentos da população que vive em situação de rua, usuários de álcool, drogas, profissionais do sexo, bem como a ampliação das outras várias formas de trabalho informal, ilegal, clandestino, sem nenhuma forma de proteção legal e social.

Os eixos prioritários para a pesquisa, as propostas de política e organização de serviços, a questão da formação de recursos humanos, bem como os novos e velhos temas emergentes, exigem do campo da saúde coletiva, e das ciências humanas e sociais aí inseridas, um novo olhar, novos objetos de pesquisa e novas perspectivas metodológicas para desenhar esse caminho.

\section{Referências}

\section{AROUCA, A. S. O dilema preventivista:}

contribuição para a compreensão e crítica da medicina preventiva. São Paulo/Rio de Janeiro: Editora Unesp/Editora Fiocruz, 2003.

BARSAGLINI, R. A. As Representações Sociais e a Experiência com o Diabetes: um enfoque socioantropológico. Rio de janeiro:Editora Fiocruz, 2011.

\section{BELISÁRIO, S. A. Associativismo em saúde} coletiva: um estudo da Associação brasileira de Pós-Graduação em Saúde Coletiva - Abrasco. 2002. Tese (Doutorado em Medicina Preventiva) Faculdade de Ciências Médicas, da Universidade de Campinas, Campinas, SP. 
BIRMAN, J. A. Physis da Saúde Coletiva. Revista de Saúde Coletiva, Rio de Janeiro, v. 1, n. p. 9, 1991.

BOBBIO, N.; MATTEUCCI, N.; PASQUINO, G. Dicionário de política. 2. ed. Tradução de J. Ferreira et al. Brasília: Editora da Universidade de Brasília, 1986.

BOLTANSKI, L. As classes sociais e o corpo. Tradução de R. A. Machado (Org.); M. A. Loyola; R. A. Machado. Rio de Janeiro: Graal, 1979.

CANESQUI, A. M. (Org.). Dilemas e desafios das ciências sociais na saúde coletiva. São Paulo/Rio de Janeiro: Hucitec- Abrasco, 1995.

CANESQUI, A. M. (Org.). Ciências sociais e saúde. São Paulo: Editora Hucitec/Abrasco, 1997.

COHN, A. O estudo das políticas de saúde: implicações e fatos. In: CAMPOS, G. W. de S. et al. Tratado de saúde coletiva. São Paulo/Rio de Janeiro: Hucitec/Fiocruz, 20o6. p. 231-258.

DEJOURS, C. A. Loucura do trabalho: estudo de psicopatologia do trabalho. 2. ed. Tradução de Paraguay . I. Paraguay; LL. Ferreira. São Paulo: Cortez/Oboré,1987.

DONNANGELO, M. C. F. Medicina e sociedade. São Paulo: Pioneira, 1975.

DONNANGELO, M. C. F.; PEREIRA, L. Saúde e sociedade. 2. ed. São Paulo: Duas Cidades, 1979.

DONNANGELO, M. C. F. A pesquisa na área da saúde coletiva no Brasil: a década de 7o. In: BUSS, P. M. (Org.). Ensino da saúde pública, medicina preventiva e social no Brasil. Rio de Janeiro: Abrasco, 1983. p. 19-35.

FIGUEREDO, J.R. Modos de ver a produção no Brasil. São Paulo/Campinas: Educ/Editora Autores Associados, 2004.

FLEURY TEIXEIRA, S. (Org.). Saúde coletiva? Questionando a onipotência do social. São Paulo: Relume Dumará, 1992.

GOMES, A. F. Desafios às ciências sociais na área da saúde. In: NEHMY, R. M. Q (Org.). Anais do I Encontro Brasileiro de Ciências Sociais em Saúde. Belo Horizonte: Abrasco, 1994. p. 23-30.
GOMES, C.M., MACHADO, J.M.H.,PENA, G.L. (org). Saúde do Trabalhador na Sociedade Brasileira Contemporânea. Rio de Janeiro:Fiocruz, 2011.

GRAMSCI, A. Os intelectuais e a organização da cultura. 2. ed. Tradução de C. N. Coutinho. Rio de Janeiro: Editora Civilização Brasileira, 1978.

LATOUR, B. Jamais fomos modernos. Rio de janeiro: Editora 34, 1994.

LAURELL, A. C.; NORIEGA, M. Processo de produção e saúde: trabalho e desgaste operário. São Paulo: Editora Hucitec, 1989.

LEAVELL, H.; CLARKE, E. G. Medicina preventiva. São Paulo: McGraw-Hill do Brasil/MEC,1976.

LÉVI- STRAUSS, C. Introduction `a l'oeuvre Marcel Mauss. In: MAUSS, M. Sociologie et antrhropologie, p. I-XXX. Paris: PUF, 1950.

LÉVI- STRAUSS, C . Structural anthropology. Nova York: Basic books, 1963.

LOYOLA, M.A. Médicos e Curandeiros: conflito social e saúde. São Paulo: Difel, 1984.

LUZ, M. T. As instituições médicas no Brasil: instituição e estratégia de hegemonia. Rio de Janeiro: Graal, 1978.

MARSIGLIA, R. M. G.; SPINELLI, S. Caracterização do ensino, pesquisa e recursos docentes da área de ciências sociais nos cursos de pós-graduação em saúde coletiva no Brasil. In: BUSS, P. M. (Org.). Ensino da saúde pública, medicina preventiva e social no Brasil. Rio de Janeiro: Abrasco, 1983. p.61-77.

MARSIGLIA, R. M. G.; L'ABBATE, Relatório da oficina "Ensino de ciências sociais em saúde. In: NEHMY, R. M. Q. (Org.). Anais do I Encontro Brasileiro de Ciências Sociais em Saúde. Belo Horizonte: Abrasco, 1994. p.131-135.

MARX, K. Contribuição à crítica da economia política. São Paulo: Martins Fontes, 1977.

MAUSS, M. Sociologie et anthropologie. Paris: Presses Universitaires de frande, 1950. 
MINAYO, M. C. de S. Contribuições da antropologia para pensar a saúde. In: CAMPOS, G. W. de S. et al. Tratado de saúde coletiva. São Paulo/Rio de Janeiro: Hucitec/Fiocruz, 2006. p. 201-230.

MORIN, E. Jornadas temáticas (1998: Paris, França: 1998). A Religação dos saberes: o desafio do século XXI. Tradução de F. Nascimento F. Rio de janeiro: Bertrand Brasil, 2001.

NUNES, E. D. Sobre a Sociologia da Saúde. São Paulo: Hucitec, 1999.

NUNES, E. D. Sociologia da saúde: história e temas. In: CAMPOS, G. W. de S. et al. Tratado de saúde coletiva. São Paulo/Rio de Janeiro: Hucitec/ Fiocruz, 2006a. p. 19-51.

NUNES, E. D. Saúde coletiva: história recente, passado antigo. In. CAMPOS, G. W. de S., et al. Tratado de saúde coletiva. São Paulo. Rio de Janeiro: Hucitec- Fiocruz, 20o6b. p. 295-315.
OMS - ORGANIZAÇÃO MUNDIAL DA SAÚDE-:

Classificação Internacional das Doenças- CID- 10, 10 a . Revisão.199o. Versão 2008. Capítulo XXI: Fatores que influenciam o estado de saúde e o contato com os serviços de saúde. Agrupamento Z55-Z65: pessoas com risco potenciais à saúde relacionados com circunstâncias socioeconômicas e psicossociais.

POMBO, O. Epistemologia da interdisciplinaridade. In: SEMINÁRIO INTERNACIONAL: INTERDISCIPLINARIDADE, HUMANISMO, UNIVERSIDADE, Porto: Faculdade de Letras da Universidade do Porto, 12-14 de novembro, 2003.

SIGERIST, H. E. The special position of the sick. In: ROEMER, M.I., HENRY E. Sigerist on the sociology of medicine. Nova York: MD Publications, 1929; 1960. p. 9-22. 